the parent. A few Aurelia of medium size were taken on the $7 \mathrm{th}$, and again on the 16th, 17th, 18th and 19th.

On May 10th a few small specimens of Tubularia couthouii were dredged at Quick's Hole, and the large stems of specimens dredged on the 17th seemed to show signs of regenerative processes. On the 11th hydromedusæ were hatched from hydroids of Obelia, and on the 13th a few were seen in the water around the station. Tima formosa was not seen during the month, though in 1896 the species was abundant in Narra. gansett Bay.

H. C. Bumpus.

\section{NATURAL HISTORY MUSEUMS (II.).}

THE MUSEOM AS A TEACHER.

The museum, by an intellectual treatment of its collections, has, as I have shown already, discharged a large part of its function as a teacher. It remains for it to provide guides and lectures. The guides can be small books, leaflets or albums. The lectures are a more important feature. They are inaugurated in many museums; the series given in Washington, under the auspices of the National Government, and those given in London by the British Museum are examples illustrating this feature at its best. Lectures demand for their best popular value a combination of a firm and thorough command of the subject, a simple and yet adequate verbal exposition which may with some, according to their exceptional talent, assume a high literary quality, and lastly ample and stimulating illustration, either in slides by projection or in natural specimens. It is unnecessary to discuss the best form of a lecture. One point can be conclusively claimed, that the feature of entertainment should not expel out of all semblance of existence correct definite instruction, and that the philosophy of the topic should not be presented in broken half-truths, but envelop the listener with the penetrating atmosphere of thought.
THE MUSEUM AS AN INVESTIGATOR.

The museum completes its scope of relations to the great world of scientific interests when it uses its resources in the prosecution of original research and in publishing that which requires publicity. Biological problems are more naturally carried on in schools devoted to that subject, but the gathering of evidences and facts in natural history, facts bearing on distribution of animals, their habits and physiology, the solution of problems in ethnography and archæology, the collecting of new and valuable specimens in geology and mineralogy, the illustration of faunas and floras, description of new species, and revision of old, are topics which naturally engage the attention of the Museum of Natural History. The series of publications that have proceeded from the Smithsonian Institution, the National Museum, and the Museum of Comparative Zoology at Cambridge, form a library of research and generous compilation almost unrivalled.

THE AMERICAN MUSEUM OF NATURAL HISTORY.

In 1867 New York was without a museum. The American Academy of Arts and Sciences had in Boston brought together collections which formed a nucleus for yearly accretions, and furnished material for study and publication. In Philadelphia Franklin had unmistakably imparted, by example and a contagious influence, the spirit of research to groups of scientific minds. The American Philosophical Society and the Philadelphia Academy of Sciences by their important papers, the accumulation of a varied store of material, and the establishment of a remarkable library, furnished the most significant monument to the imperishable ardor of the great printer.

In Washington Smithson had laid the foundation of a museum and established a 
bureau of publication and exchange which brought into correspondence the scientific workers of the world. In Cincinnati, a city rejoicing in a neighborbood which yields the most multifarious vestiges of a past life, a museum had been organized, and here Anthony, a pupil of the elder Agassiz, held sway over a local group of conchologists. In Albany the fruits were chiefly garnered of the classic survey of this State, that, inaugurated in 1836, marked an era in the history of geological science in this country, and deciphered an alphabet in geological formations that has been applied to all its other sections. In Chicago a museum under the genial inspirations of Stimpson had assumed mature dimensions.

There were clubs of collectors in New York, and the K. K. Club of Brooklyn is yet pleasantly remembered by its older citizens, who may have there displayed before envious eyes a rare cypræa, a precious volute, an unsurpassed cone or a unique olive. A philosophical society had, indeed, expired in New York after issuing an exhaustive claim to continued existence. The New York Lyceum succeeded it, and here Torrey, Draper, Wheatley, Redfield and Dekay created the elements of a scientific association. In 1865 its collections of considerable value were destroyed by the flames which razed to the ground the old Medical School of the University, but later it sprang into prominence under Newberry, and maintains to-day a prolific scientific vigor under the guidance of Julien, Osborn, Britton, Kemp, Dean and Doremus.

Such preparatory stagest brought into notice the enthusiastic designs of Mr. Waterhouse Hawkins, an anatomist of repute and an artist whose imagination had reached an extreme point of fertility from the study of extinct forms of life. Mr. Hawkins captured the ear or the fancy of the officials of the Department of Parks, who involved their own rather mundane designs upon
Manhattan Square with Mr. Hawkins' terrifying restorations, and the result of this somewhat incongruous union was to be a sort of Sydenham Palace. Here was to be a bear-pit, amphitheatrical and boundless, surrounded with caves surprisingly natural; above this was contemplated a huge circus of rock becomingly wild and impressive, while a company of beavers, beyond this Rabelaisian structure, were to build dams fast and large enough for the sensational needs of a metropolitan audience. We read in the Evening Mail, Wednesday, October 27, 1869 : "Caves with graceful tenants will surprise at every turn, tiny cascades will tumble down the rocks, wonders of the finny tribes will glisten in miniature lake and sedgy pool, and among the shadowy foliage overhead rare birds of gorgeous plumage will talk to us in unknown tongues." At this point Mr. Hawkkins came in. There was to be a gloomy and half subterranean receptacle for his restorations, a sort of fossil catacombs wherein the visitor, suppressing his dismay and encouraging his understanding, would wander about through shapes of pre-Adamite existence, and escape again into the light of day like Marcellus and Bernardo, 'distilled almost to jelly with the act of fear.' New York was spared this unnecessary and theatrical episode.

R. L. Stuart, R. J. Steward, Theodore Roosevelt and H. Haines established the American Museum of Natural History. Professor A. S. Bickmore was associated with its very first years, having been engaged as its first Superintendent, while the venerable name of John David Wolfe as its first President, supported by a long list of prominent citizens, guaranteed it the requisite recognition in the State Legislature. Without pausing to recall the uneventful days of its inconspicuous life in the old arsenal in Central Park, I pass to that summer day in 1874 when the corner 
stone of the first section of the present imposing structure was laid. I beg to quote from a paper on the Museum prepared by me in 1883: "It was in June. A large platform covered the newly-laid walls of the foundation, and above this rose their unfinished and irregular edges, inclosing a space crowded to its limits with expectant guests. A canopy over all tempered the propitious radiance of a summer sun; platoons of police kept open broad avenues. of approach, and the constant roll of equipages and the occasional appearance of groups of distinguished men lent to the occasion an unusual and gala character. The scene was, in reality, not without a certain impressive and picturesque interest. Without the inclosure, the square, then broken by outcropping strata of gneiss rock and valley-like basins, was black with throngs of men for whom was then instituted a place of beneficial recreation; within, an assembly of beauty and culture, wisdom and executive prerogative, engaged in a ceremony contemplating honor solely to the genius of modern civilization."

President Grant laid the corner stone; Governor Dix spoke, and the great and wise Henry saluted it in a prophecy of mingled hope and admonition. I have elsewhere reviewed the nature and importance of the collections then displayed, and it is now auspicious, without wearying your patience, to explain the greatly changed conditions that prevail within it and its enormously expanded prospects and opportunities.

Upon the death of President Wolf Mr. R. L. Stuart succeeded to the presidency, and upon his demise, in 1882, Mr. Morris $\mathrm{K}$. Jesup. It is really within the period of the latter's presidency that the Museum has entered upon the prerogatives and functions of a great museum. At the outset of an outline of the Museum's status it must be realized that in its relations to the city it is partially a tenant of the city and partially a beneficiary. The city furnishes the corporation known as the American Museum of Natural History with a building adequate for its purposes, and pays to it also an annual sum sufficient for its proper maintenance and the care of its collections. On the other hand, the corporation represented by its officers and trustees furnishes to the people of the city free access (under the reservation of two pay-days a week) to its collections, which it engages to label and display so as best to promote the instruction of its visitors. There are five scientific departments in the Museum, a library, a business and a clerical administration.

The five scientific departments cover almost entirely the area of Natural History, and embrace Forestry, Mammalogy and Ornithology, Entomology, Invertebrate Paleontology, Invertebrate Zoology, Mineralogy and Economics, Ethnography and Archæology. Objects and collections are secured by donation and purchase. The gifts which have enriched the Museum are princely. Mr. M. K. Jessup, the President, has given the exhaustive collection of American Forestry ; Mr. J. Pierpont Morgan, the Tiffany collection of gems ; Miss Catherine Wolf gave the Conchological Library of Dr. Jay, which is the nucleus of the present greatly enlarged collection of books. Mrs. Margaret Schuyler Elliot gave her husband's superb cabinet of bred Lepidoptera; Dean Hoffman, the exhibition collections of North and South American butterflies; James Angus, a varied collection of representative entomology; W. Schaus, the Old World moths. In ethnology and archæology the Duke de Loubat, Henry Villard, J. Pierpont Morgan, B. T. B. and Frederick Hyde and Heber R. Bishop have given most valuable collections and supported expeditions, as the important one of H. Bandelier in Peru ; while Mr. Jessup has inaugurated and maintained, and is 
now administering, the expeditions to Mexico, Siberia and Alaska. Purchases upon a most munificent scale have secured such large collections as the Sturgis, Emmons, Terry and De Morgan in ethnology. and archæology, the Haines in conchology, the Hall in paleontology, the Spang in mineralogy, the Baily and Bendire in oology, the Maximillian and Elliot in mammalogy and ornithology, the superb Elliot library on birds; and innumerable smaller purchases are yearly adding to the beauty and completeness of the cabinets. Perhaps the most astonishing and original exhibit contained in the Museum to-day is that of vertebrate paleontology. Professor H. Fairfield Osborn has practically created this department. He has supported it in its work in the field under Dr. Wortman, and he has brought to its installation a sympathy for the needs of the visitor and student, an unerring sense of correct and attractive arrangement, and he has stamped it with the impress of deep learning.

Amongst the very beautiful objects of the Museum halls, the realistic groups of birds and animals challenge a delighted notice, These admirable extracts from nature show the habitat of the animals reproduced with microscopic care and verisimilitude, the animals themselves in flight or motion or arrested in surprise or interest. The art of taxidermy has taken a high and justly celebrated place in the American Museum of Natural History, and Messrs. Rowley and Smith have felt the responsibilities of their keenly critical position. There are gems of taxidermy from the hand of Jules Verreaux where the apt instinct for anatomical relations reveals the character of the creature, where angularities of structure are not forgotten, and smooth contours are entered by lines of muscular or ligamental modelling. Taxidermists are apt to overstuff; if the subjects are large they are fattened with superabundant straw until, like Falstaff, they are ' mountains of mummy ;' if small, converted into rolling pins, or, as Flower says, are 'wretched and repulsive caricatures, out of all proportion, shrunken here, bloated there, and in impossible attitudes.' Taxidermy, like sculpture, is a study of the relations of muscles; with little difficulty it becomes the protean art of making pin cushions.

The Museum of Natural History in London is regarded to-day as the most perfect. representation of an ideal museum of natural history in the world; after it the museum in Berlin, and, in about equal rivalry for the second place on the Continent, those of Vienna and Paris. The care with which the first two have elaborated the presentation of groups of birds and mammals afforded the suggestion for the groups now shown in the American Museum. These were at first largely created by the cooperative efforts and skill of Jenness Richardson and Mrs. Moggridge, an Englishwoman who had worked at South Kensington. The taxidermy at all these museums is of no higher order than that displayed in the American Museum of Natural history. The groups are more varied, are larger, and in many cases, as at Paris, are placed in more theatrical relations to the spectators. Such groups compose a feature wonderfully attractive, and are really to a large superficial class of visitors the most appreciated and helpful form of exhibit.

In the British Museum the influence of environment, the modifications of texture, and the progressive changes in dermal appendages and skin, together with ample morphological illustration, supplement these pure nature studies and embody a magnificent lesson in zoology. Such advances Dr. J. A. Allen contemplates in the American Museum in New York.

The detailed or even general description of the collections is impossible in a sketch devoted to blocking out the conformation 
simply of this great Museum. They have grown and spread and their multitudinous aspects defy compression within the limits of a reasonable and readable essay. But one characteristic of the present development of the Museum should receive attentive consideration.

President Jessup has, I presume, upon mature deliberation thrown the energies of this institution largely in the direction of ethnographic study. Expeditions have been and are to-day despatched into distant sections of indigenous culture to bring back the implements, the dresses, the idols, art and industry of savage or semi-savage or pre-historic races. Comparative studies in culture, religion, language, myth, art, are to be instituted, and the converging lines of such research are to be directed towards that baffling problem of the origin of the American race. American archæology is to be explored and its many phases, from the Indian arrow head to the Palenque altar pieces and the slightly varying cultures of Toltec, Miztec, Zapotec, Nahuatl and Maya, examined and substantially illustrated.

While it is an affected propriety to say ' the proper study of mankind is man,' and while we may with earnestness recommend the curiosity which hunts diligently for any light which reveals the relations of races, their origin, migration and changes, yet the endless collections of pottery, stone implements, textiles, weapons, industrial work and religion might often seem judiciously discouraged. A museum of natural history cannot conveniently or profitably merge its character into that of a museum of comparative ethnology and archæology. It must retain preëminently its office of revealing the realm of nature rather than that of artifice. It must exhaust its resources in a search for the marvels of the animal and mineral kingdoms, and for the revelations of geology. It must increasingly regard its mission as concerned essen. tially with the lessons and the beauties which are involved in and which decorate the faunas or floras of the earth and those. which challenge our enthusiasm in the marvels of crystals and the story of the globe.

The publications of the Museum embrace a series of bulletins now in its ninth volume, and a series of memoirs scarcely begun. They are liberally exchanged with foreign: and domestic societies, with individual workers, libraries and institutions of learn. ing. They comprise a great diversity of subjects and are a record of original work. of supreme interest. The library has by growth, exchange and gift reached a commanding size and numbers thirty thousand volumes.

The Museum has formed the most flatter. ing alliances with societies that meet within its walls, and with the University of Columbia, which sustains a course of winter lectures in its lecture hall. It is one station of the free lectures of the people under Dr. Leipziger, and its platform and admirable equipments for illustration, designed by $\mathrm{Mr}$. L. C. Laudy, are in constant requisition for lectures on travel, botany and natural history.

The lectures given by Professor A. S. Bickmore under the auspices of the Department of Public Instruction are first delivered here, and afterwards with the accompanying slides distributed to the State Normal Schools and to the superintendents of education in towns and incorporated villages. The educational activity of the Museum is thus seen to be commendable, and, while scarcely on a level with the superabundant and richly varied instructions given by the Brooklyn Institute, its resources in illustration somewhat over-weigh the tireless ingenuity with which the area of possible knowledge is explored by the directors of the institution at Prospect Park. Material is being steadily accumulated for original investigations, and in the De- 
partment of Zoology such 'Study Series' have reached surprising dimensions. These series are strikingly accumulated in the British Museum, and their important bearing upon the scientific welfare of the Museum was expressed by Professor Flower in these words. He says the Study Series " contains all those exceedingly numerous specimens (in many groups, the great bulk of the collection) showing the minute distinctions which are required for working out the problems of variation according to age, sex, season and locality, for fixing the limits of geographical distribution, or determining the range in geological time. It is this part of the collection that zoologists and botanists resort to, to compare and name the animals and plants collected in expeditions sent to explore unknown lands; to work out biological problems of the highest scientific importance, and generally to advance the knowledge of the science. In fact, these reserve collections, occupying comparatively little room, kept up on comparatively little cost and visited by comparatively few persons, constitute, from a scientific point of view, the most important part of the Museum, for by their means new knowledge is obtained, which, given forth to the world in the form of memoirs, books or lectures, is ultimately diffused over a far wider area than that influenced even by the exhibited portions of the Museum. Indeed, without the means they afford, the order, arrangement and power of imparting knowledge which the galleries possess would not be possible."

With such a compressed summary of the salient features of this Museum, which it is hoped will yearly grow more consummately into the best expression of a museum of natural history, I ask your forbearance, though in asking it $I$ am merely anticipating your natural wishes, in considering how practically helpful this institution is in raising the popular standard of thought or desire. My own views on this question are very simple and emphatic. There are very unnecessary exaggerations of the influence of a museum. Upon some people it simply produces surprise. Its size, the diversity of its contents and the unintelligible nature of its labels produce in them a confusing consternation, consternation in which are discernible some self-reproaches for neglect of their own culture, considerable astonishment at that of others, and a pervading atmosphere of wonder as to 'how much money do you suppose it's worth.' Now this class is numerically large. It includes young, middle-aged and old, and while, of course, upon them, in ratio to their peculiarities of mind and disposition, the survey of well-arranged collections must leave wholesome, pleasurable and, perhaps, instructive impressions, the sum-total of all of their impressions will never materially change one way or another the intelligence of a community. A museum, or the directors of a museum, must indeed remember that it is a place essentially of recreation for the great majority. This recreation is far from unimportant. It is remedial, sanitary and of moral efficacy. But I can scarcely believe that it especially instructs. It opens people's eyes, gives them an increased respect for knowledge, and probably amongst parents fortifies their intention to give their children all the education they can afford to give them. I do think they derive certain emancipating ideas about time and creation, and are made probably a little more receptive of progressive thought. I allude, of course, only to scientific museums. The recreation obtained in art museums is more valuable to this class than that secured in the museum of natural history. The material of the art museum appeals more obviously to the eye, thence to the mind and thence to the memory. It involves so many illusions to taste, reading, association and experience. 
The second and remaining groups are included in the number who have met these objects of study in the class room, the lecture hall, are collectors, or from reading or conversation, or any other line of contact feel an interest in the specimens themselves; in their arrangement and in their elucidation. This is a respectable number and from the nature of things is constantly growing. But this observation emphasizes the relation in which the museum stands to education in natural history. The intelligent constituency of a museum of natural history are those who know something about its contents. And the extension of natural history study in the schools or colleges is directly promotive of the interest of the museum. The duty, then, of the museum is unmistakably to justify such extension of study by its own ample and adequate and lucidly prepared collections.

This view receives confirmation in the experience of the Carnegie Museum at Pittsburg. The first sentences of the report for 1896 of this institution contains the following paragraph: "With the opening of the second year of the Carnegie Museum the institution found itself occupying a most favorable situation. Its growth during the first year had been phenomenal. The public mind, however, had not kept pace with its progress. While the attendance was always good, the people seemed to make no serious study of the many interesting collections. This was particularly the case on the part of the younger visitors, who came frequently but seemed rather to take a general view than to make a careful inspection." To awaken the critical interest which seemed absent, the Museum Committee conferred with the Superintendent of Public Schools of Pittsburg, and as a result offered a prize essay competition for the pupils of the high schools and high school classes of the public schools. The competing essay was to take the form of a letter, limited to two thousand words in length, from the various contestants to. a friend describing a visit to the Museum. The flattering result of this scheme is thus described in the same report:

"No sooner had the circulars been published in the newspapers and distributed to the pupils than the expected result ensued. The pupils of the two chosen grades flocked to the Museum, accompanied by parents and friends, and the habit of careless sauntering immediately gave place to minute and studious observation. Those who designed to compete for the prizes used their note-books for describing the objects, having been cautioned by the committee's circular against making mere lists of the labels or the use of technical language, and informed that the committee preferred ' an intelligent, comprehensive and general description rather than itemized statement or complete catalogue,' nor was this improvement in the method of studying the museum confined alone to the contesting pupils, for the whole body of visitors was observed to take a deeper interest in the inspection of the objects."

In other words, the collections of the Museum become objects of study, of reflective observation, and probably are memorized as to their nature, meaning and relations when a motive of interest prevails to such an end with their visitors. In the accidental case adduced it was a motive of ambition, with some mercenary considerations partially involved. But the motive that can be most generally invoked is one springing from previous knowledge. We all naturally examine new illustrations of what we have studied, what we have collected, or what we have heard about. The profuse admiration of men and women, boys and girls, in the halls of the Museum, over the shells and the birds, and gems and minerals, means almost nothing. Remove these hysterical eulogists to the outside of 
the Museum, distract them for a moment by a mechanical carriage, a street procession or an April shower, and I doubt if the distinct recollection of one shell, one bird, one gem or one mineral could be satisfactorily traced upon their minds.

Of course, the Museum helps the great populace; it gives them a pleasant and desirable environment of order and beauty and interest, but its educational power in a specific sense is limited almost entirely by knowledge, previously acquired amongst its visitors, of the things it contains. But let no maleficent construction be given to these words. The Museum of Natural History is a wonderfully helpful adjunct to all forces leading to sanity and happiness. To the most untutored it brings delightful revelations of the variety and the mystery of nature, and to those who love that wide retinue of facts and impressions which the fields and the woods, the tenanted air and the resounding sea, constantly yield, how full and eloquent it seems !

The consecrated attitude of mind which in Wordsworth's Ode on the Intimations of Immortality, expressed its ecstacy in the wonderful lines:

\footnotetext{
"And O ye fountains, meadows, hills and groves, Think not of any severing of our loves !

Yet in my heart of hearts I feel your might ;

I only have relinquished one delight,

To live beneath your more habitual sway ;"
}

or that intensity of absorption with Nature which made the hand of Thoreau pen these salient phrases in his Cape Cod: "We often have to think now of the life of men on beaches-at least in mid-summer when the weather is serene; their sunny lives on the sand, amid the beach-grass and the bay berries, their companion a cow, their wealth a jag of driftwood, or a few beach-plums, and their music the surf and the peep of the beach-bird ;" both of these relations to Nature so contrasted, rediscover in the museums of natural history the stimulus and the justification to their satisfying joys.

L. P. Gratacap.

american Museum of Natural History.

GEORGE BAUR.

The telegraphic despatches have brought us the sad information of the death of Dr. George Baur, of the University of Chicago.

About a year ago Dr. Baur was compelled to quit his work and to seek rest. It has been known to some of his friends that his state of health was not improving, but his death must come as a surprise to all. Some of his more intimate friends will doubtless give us a biographical sketch of this young, but already eminent naturalist. The writer, who enjoyed somewhat close association with him for a space of four years, desires to pay a tribute to his memory.

Dr. Baur was a native of Germany and he took his doctor's degree at the University in Munich in 1882. Here he studied histology under Dr. Kupffer and paleontology under the distinguished Dr. Karl Zittel. He had previously spent some months with Dr. Leuckart in Leipzig. He gave special attention to osteology and vertebrate paleontology, and his inaugural dissertation was entitled 'Der Tarsus der Vögel und Dinosaurier.' It appeared in the Morphologisches Jahrbuch for 1882.

Unless the writer is in error, Dr. Baur came to this country in 1884 . He became assistant to Professor O. C. Marsh, in the paleontological laboratory of the latter at New Haven, and continued in this position until January, 1890. During this period he devoted his energies to the fossil reptiles, a group to which he ever afterwards gave especial attention, and upon which he published a number of papers. During the summer of 1890 he spent some time in western Kansas, where he collected fossil reptiles and fishes for Dr. Zittel. Shortly after leaving New Haven he received a call 